\title{
Religion and Gender Roles in Africa: A Case Study of Agricultural Patterns in Nike Primal Community
}

\author{
Uchechukwu Monica Ejim \\ http://dx.doi./org/10.4314/ujah.v18i2.5
}

\section{Abstract}

Gender roles are the apportioning of certain roles to a particular sex by society. This is quite different from gender disparity which promotes the ideology that one sex is better than the other. They are gender ideologies which can be deconstructed. In some primal cultures however, they were imbued with religious undertones and up scaled to divine mandate in order to give them legitimacy and ensure adherence to them. In this regard, African primal cultures were not left out. The problem then, is that these two ideologies are most times mixed up. And at other times, gender role has been understood as one of the tools of gender disparity. This research is poised to find out if the apportioning of certain roles to a particular sex by society has always been a product of patriarchal tendencies and of negative consequence to the society. Using historical methods, this paper tried to answer the above question by reviewing a cultural practice in Nike primal community that consisted in the allocation of certain farm crops to a specific gender. The result of the review showed that gender roles have biological basis to an extent, they can be comforting; they guided the members of the society through the tricky business of living. It was productive and beneficial to individual affirmation and the survival and progress of society and will also serve the present society in the same vein if the element of rigidity is removed. But it also existed side by side with gender disparity and other patriarchal tendencies that were detrimental to the survival and 
progress of society. The theoretical frame work operative here is feminism, and the key words are religion, gender roles, patriarchy, culture and primal communities.

\section{Introduction}

Religion is an elusive concept and has no single definition that suits everyone. This, according to Madu (1996), is because as a phenomenon, it means different things to different people depending on their perspective or approach, and as a concept, it can be used in a plethora of senses. The solution therefore as far as giving a definition of religion is concerned seems to be to identify one's perspective and then define it to suit the current purpose. In line with the above enlightenment, religion in the context of this paper will toe the line of scholars of sociological tradition like Metuh (1987, p. 13) who write that "religion comprises an institutionalized system of symbols, beliefs, values and practices focused on questions of ultimate meaning". It is in this context that one can begin to understand why in the past and until now, religion has continued to be a major anchor for interaction in most societies. At times too, individual roles are given religious interpretations or placed within the ambit of religious sanctions. It is in this regard that Agha (2012, p. 89) sees religious beliefs as significant for "social solidarity" and "moral patterning of the economic life of the people".

Similarly, Peil (1977, p. 213) defined religion as "the belief systems, moral norms and values held by members of a society". She also described religion as "an integral part of culture". If however, one is to opt for Tylor's minimal definition of religion as a belief in spiritual beings, it would be easier to see religion influencing the other aspects of culture like moral norms and 
values which forms part of it in a broader sense. As Parsons (1951: 81) rightly observed, religious belief systems has the ability to legitimize value patterns. That is to say that they give individual members of society criteria for choosing one value against other. Accepted patterns of relationships in the society are interpreted as moral norms, while the moral norms themselves in the form of taboos and codes form part of the relationship to the sacred. For instance, the Jewish culture is known for their relegation of women to the background. It is not surprising then that their myth of creation in the book of Genesis clearly stipulated that God made woman with just one rib from man, that after the fall of man, the woman's punishment included, "he (your husband) shall rule over you" (Gen. 3: 16), or that Paul, a staunch product of that tradition ensured in his instructions to the early church that women are told clearly to shut up (I Cor. 14: 34-35).

Linton (1945, p. 213) defined culture as "the way of life of the members of a society; the collection of ideas and habits which they learn, share and transmit from generation to generation". Kluchkhohn (1951, p. 33) summarily defined culture as a "design for living". Haralambos and Heald (1990, p. 3) also posited that culture "defines accepted ways of behaviour for members of a particular society". Suffice it to say that gender roles as part of culture relate with religion at several levels. Firstly, both of them are elements of culture. Secondly, in some societies, sex roles are given religions interpretation, they gain moral status thereby becoming part of the people's relationship with their deity.

Gender roles have been defined by Dolen (2008, p. 1) as "expectations about the behaviour of males and females". Examples of such expectations is that men should work outside the 
home, do the heavy work, fight the wars, dominate most if not all spatial ability jobs like mathematics, Engineering, Architecture and so on thereby, controlling the most powerful institutions. Women are expected to bear and nurse babies, care for the young, work in or near the home, do the family cooking and so on. Even when they work outside the home, they are expected to work in occupations that deal with children and interrelationships between people.

Gender roles as depicted above differs from what Mabili (2013, p. 2 ), identified as "gender disparity". He defined gender disparity as the inequality that both the male and female gender face as the African custom does not place both sexes at common levels". This social reality is manifested in some communities where the female child's future is seen as expendable and she becomes most useful as a tool to help support the development of the male child. For instance, there have been situations where girls are given out in early marriage (sometimes against their will) so that the dowry so realized can be used to train a male child.

This gender disparity also manifests in laws of inheritance, leadership, employment opportunities and religion except in rare cases where women are priestesses of a goddess or in matrilineal cultures. Sex role stereotyping may sometimes serve the purposes of elements of patriarchal tendencies and gender disparity within a community, but they are two different things. While the former is based on nature or biological structure, and can serve society positively, the later is based on conscious efforts by the perpetrators of patriarchy to ensure that the status quo is maintained. Gender disparity is capable of robbing society of useful manpower and impeding development. The motto of gender 
disparity is to show that one gender is better than the other, but gender role shows, not that one gender is better than the other, but just points to the fact that they are different. Primal communities as used in this paper refers to the traditional setting of communities, the way they were before the advent of contemporary occupational practices. The main thrust of this paper therefore to demonstrate how in an African primal community, gender roles, which forms part of the moral codes but devoid of patriarchal tendencies served individuals and society positively, bring out inherent negativities, and project recommendations on how it could benefit the present African societies.

\section{Sex Role and Biological Structure}

As much as possible, efforts shall be made in this paper not to get embroiled in the battle that have raged on for several decades between extreme feminists and their opponents regarding the actual source of gender roles (Dolen 2008, p. 11). It is however pertinent to point out that though gender role or stereotyping may sometimes serve the purposes of gender disparity and patriarchy (Amadiume, 1987; Uchem, 2001 among others), gender roles are foremost based on human nature, the biological structure of the different sexes. There are things that women generally do better and so will be more productive if they engage in such enterprise and vice versa. If this assertion is true, there is no need then to throw the baby away with the dirty bath water.

Pease and Pease (2001, p. 21-23) came up with an example that amply illustrated the point being made here. According to them, it has been discovered scientifically that woman have a wider peripheral vision, while men have tunnel vision that covers a longer distance. This difference is attributed to the fact that women 
not only have a greater variety of cones in their retina but also a brain software that allows her to receive an arc of at least $45^{\circ}$ clear vision to each side of her head and above and below her nose. It is a known fact that in some women, peripheral vision is effective up to almost $180^{\circ}$. On the other hand, a man's eyes are larger than a woman's, and his brain configures them for a type of long distance tunnel which means that he can see clearly and accurately directly in front of him and over greater distances almost like a pair of binoculars.

These differences in vision have important implications for the capabilities of each gender. Pease and Pease (p. 21) citing car insurance statistics in the United States of America showed that female drivers are less likely to be hit from the side in an accident at an intercession than male drivers. While a woman can see better in the dark than a man especially at the end of a spectrum of light, a man's eyes allow for better long distance vision over a narrower field, which gives him much better and therefore safer long distance night vision than a woman. Given the above biological structure of male and female vision, it would be most beneficial for a couple or group on a long trip to have a woman driving during the day and a man during the night. It might also amount to fool hardiness for the female to contest such arrangement just to prove that "what a man can do, she can do better.

Admittedly, the primal African communities in allocating roles to the different sexes, may not have possessed certain scientific knowledge as regards the biological set up of the different sexes but conjecturally, they could have gained the same knowledge of human nature through experience, observation and intuition. 


\section{Profile of Nike Primal Community}

Nike is located in Udi cuesta of Enugu State, Nigeria. It is made up of 24 villages and bestrides two local government councils at present namely, Enugu East and Enugu North, with Enugu North containing Ogui alone, one among the 24 Nike villages. The 2006 population census put the population of Enugu State at 279,089 and the area at $383 \mathrm{~km}^{2}$ (Wikipedia, n. d, para 4). It has to be noted however that this population figures include immigrants from other parts of the state and beyond because of the proximity of the town presently to the Enugu urban centre. Three different myths are told to explain the origin of Nike people. The most plausible among them however, is the one that posits that Nike was a confederation, an assemblage of settlers from different locations who settled at different times. There were farmers, hunters, traders brought together by the mutual quest for survival (Nnamani, 19991, p. 13).

The primal religion of Nike people apart from the recognition of the creator or Supreme Being Awuwa and its antithesis Uluchi is mainly focused on the Ani cult in its various gradings (Kalu, 1996). At the apext is Anike nwa Awuwa patronized by the whole villages. It is perceived to be the earth goddess and its priest is usually a female. Second in the hierarchy are the deities representing the earth of each village, so that in Amorji village, there was $A n i$ Amorji, in Iji village, Ani Iji and so on. At the level of the family, there was Ani Mbalezi patronized by each family. The deities were the custodians of morality and punish offenders accordingly. They were appeased for taboos broken, and is sworn by when individuals wish to prove their innocence.

Economic activities in Nike Primal Community comprised mostly of farming, both animal husbandry and crop farming; individual 
and collective hunting, palm wine tapping and craft. Nike was important on the pre-colonial trade routes of Igboland and was involved in trading of horses, cows, farm produce, coral beats, camwood, and slaves during the era of slave trade. Their participation in the last form of trade continues to be evident in the structure and nature of consanguine relationships in Nike today (Kalu, 1996).

\section{Gender Roles as Moral Codes}

As regards crop farming which was the mainstay of economic activities in Nike primal community. The various species of yam with the exception of Abana were cultivated by men. It was a taboo for a woman to be seen planting or harvesting yams. It is viewed as a disruption of the spiritual and social order and the culprit is mandated to appease the gods immediately or face ostracism from the community. It may be pertinent to note here that apart from its religious connotations, the allocation of farming of yam to men, made sense from a biological point of view because yam farming is a strenuous activity requiring a lot of energy. Big mounds are made to give room for the developments of tubers, true branches are cut, trimmed and positioned for the yam tendrils to climb on, and extensive digging is required to harvest the matured tubers. Apart from yam farming, there are also other activities that women do not engage in. Such economic activities include, wine tapping of climbing the palm tree for any reason. A cursory look at most of these economic activities that woman are not allowed to engage in shows that they share one thing in common, they are strenuous and sometimes dangerous ventures. 
Nevertheless, a few women especially widows as a matter of circumstance have had to cultivate yams. The woman in this case is expected to invite a male relation to plant and harvest the yams for her. She also has the alternative of buying labour. In a situation where she could not have recourse to any of these options, the community and even the gods show a lot of flexibility and understanding in turning a blind eye when she takes a young son or male relative who is obviously too young to hold a planting trowelapashi, to farm claiming that he was going to plant or harvest her yams. In this kind of scenario, it is usual to hear a fellow villager who met them on the way exchange banters as follows, "oh your little husband is going to plant yam for you" and the woman would reply in the affirmative. That way, culture is appeased and her own convenience is taken care of.

But, the question that comes to mind here is, why the charade? Was it aimed at deceiving the gods who are supposed to be all knowing or to appease the ego of patriarchal elements within the community? However, cultivation of the rest of the root crops, cocoyams, enyu, vegetables, maize, melon, the various species of beans, $e d u$, the gathering and processing of forest resources like Uchakuru, oil bean, ogbono, palm products and so on as well as their marketing within the locality are seen as female enterprise. A man who engages himself in them may be mocked, but, there are no taboos against men's involvement in such ventures.

\section{Nike Agricultural Cycle and the Hunger Gap}

The yam harvest usually took place towards the end of July, and the new yam festival followed around August. During the harvest and a few months after, people generally speaking have plenty to eat especially in families with males that cultivate yams. The 
widow whose children were still young may also count on gifts of yams from close relatives or buy cheaply from the local market. There is relative abundance at this period because yam was not only the most prestigious farm crop at the time but also the staple food of the community during the period under review. This period of comfort lasts till the end of the planting season around April. It lasts this long because, within the planting season, even when the main stock of yams had been exhausted, some of the yam seeds rejected for one reason or the other - mpicholo, were still eaten by people. In fact, it was considered to be a delicacy eaten with red palm oil and salt. This is also the period during which the yam shoots and women begin to intercrop in the portion of their husband's farm allocated to them.

The period between the end of the planting season and the next yam harvest is conceptualised in this paper as the 'hunger gap'. It is known in Nike parlance as Egbanabo. It is usually characterized by serious work in the farm, which consists in the three sets of weeding namely, ukalakpo, ugbegbo, and ugbeto; yam staking and so on. More importantly, there is acute or mild food shortage at this time depending on the previous year's agricultural yield. The types of food available at this time of the year were mainly those afore mentioned women crops. Secondly, there are usually more mouths to feed because labourers may be employed on the farms from time to time, and had to be fed as well.

Many scholars have reported phenomena similar to the hunger gap in other cultures within Nigeria and in other parts of Africa. For instance, De Garine (1991, p. 82), wrote on what he called, seasonal food shortage, finance and socio economic change among the Massa and Mushey of Northern Cameroon. He described this 
seasonal food shortage as "deprivation due to a detrimental shift in resource availability. It is perceived by most or all the actors as being cyclical or repetitive and therefore at least partially predicable" (p. 95).

\section{Women as Sustainers}

It is traditionally assumed in Nike primal society that the man has done his bit during the harvest and post harvest months as far as feeding the household is concerned. Therefore, the onus now falls on the woman to a large extent to ensure that the family does not starve till the next yam harvest. In as much as some wealthy husbands may still bring out yams reserved in their barns to support the woman once in a while, it is believed that it is her exclusive responsibility to sustain her family nutritionally during the hunger gap. This expectation explains the origin of a popular adage in Nike - Zuom nudumi; nzuоти nu negbanabo, which is a subtle warning from women to their husbands not to forget their duties by them during the harvest and post harvest season if they do not want to starve during the hunger gap.

At the family level, women employed indigenous knowledge interestingly as strategies for poverty alleviation. For instance, cushioning one's family against the effect of hunger gap involves an adequate knowledge of preservation methods. Cocoyams from the previous year's harvest are cooked intensively, dried under the sun and with the help of heat from burning heavy logs of wood, pieces of yams that would have wasted during the time of plenty are peeled, gathered, dried, ground and stored as edible flour alibo. Maize and cassava are also broken into bits or ground into flour after drying item to be eaten with soup as foofoo or with vegetables during the hunger gap. Women who have a surplus of 
these products also sell off some of them and use the money so realized to purchase condiments.

Coping mechanisms also include planting vegetables beside water sources - mgbamili, and the gathering of, use and sale of forest resources. The woman is expected to work very hard on her farm so as to produce enough food that will enable her face the challenges of providing nourishment for her family effectively during the hunger gap. Rationing and managing her food stock so that it sustains her family throughout the seasonal food shortage also requires a lot of ingenuity on the part of the woman. In fact, in Nike primal community, one of the criteria for choosing a wife is her envisaged ability to work hard, produce and preserve food so that she can be confidently relied upon to take her family over the hunger gap each year. It may be pertinent to note here that women wielded considerable power within this period of seasonal deprivation as they more or less control the economy of most families. Polygamy at that time was also perceived as a positive measure because, among other benefits, it ensured that the feeding of a man during the hunger gap is shared by more than one woman thereby making the burden lighter.

Iyam (1998, p. 160) reported a situation similar to that which existed in Nike primal society in Biase. There he observed that though men controlled the allocation of the major means of protection which is land, a Biase man still felt justified in his anger if his wife does not feed the family just because he had given her a portion of his farm to inter crop cassava and obiara. 


\section{Discussion}

Women in Nike primal society suffered under the effects of gender disparity and patriarchal tendencies. This is similar situations exist in many other cultures even in the present dispensation. They are for instance denied a share in communal or kindred owned means of production life land, economic trees and so on. Things are shared among the males only and this most probably, perpetrated the notion of gender disparity in the minds of the people. Male children become more desirable to the extent that a woman who had only female children view her life as a tragedy, and society judged the success of a married woman by the number of male children she was able to add to the kindred.

That is not to say that women were denied access totally to the means of production. Though they did not own land, they reserve the right to be given a portion to cultivate they asked. They are also supposed to be given a portion of their husband's farm to intercrop each planting season. They may not own economic trees (except the ones planted by themselves), but they manage and process their products.

In as much as a woman occupy the exalted seat of priest of Anike nwa Awuwa, women are generally alienated from leadership and major decision making bodies in the community except in their capacity as Umuada, a forum of daughters of the community or kindred. Even under this forum, their contributions are still accepted at an advisory level by the men. The present tense is used here because the situation has not really changed much since then. These social constructs aimed at suppressing women, which also robbed the society of useful inputs that some talented women would have made to society have persisted to a great extent till the 
present day in spite of social change. The conditions described above are quite different from the practices of gender role specification which in its pure state, served society well especially in the sphere of production.

\section{Recommendations}

1. Taking a cue from Nike primal community, women made vital contributions to the survival of the group in spite of their limited access to means of production engendered by gender disparity. In as much as each sex is advised to stick to the kind of things they do best in order to maximize output, it is important that everyone should be given a level playing ground. Sharing of communally owned property to male members of the community only cannot be justified under any guise. Women in their own rights should also be allowed equal access to capital and other means of production in the present dispensation. This will enable them excel in those areas they are conditioned to do well for the sake of themselves and the progress of the entire society.

2. The motive behind apportioning of roles to different gender becomes suspicious when one encounters the kind of situation narrated earlier with regard to Nike primal community. A woman is said to have committed a taboo if she cultivates yam honestly (if she is competent to do so), but her action is overlooked if she tactically takes a young boy along to the farm though everyone knows she did all the work. If the gods are actually involved, it is expected that they would have seen through the trick and punished the offender accordingly. It becomes obvious at this juncture patriarchal tendencies are behind such rigidity. It should be kept in view that sometimes, ambiguities occur in nature. In extreme cases, he hermaphrodites have been born, these are people who 
present the physical characteristics of one gender but have the internal constitution of another. In milder cases, there have been people who posses lots of hormones that normally belonged to the opposite sex. Such persons have been known to perform exceptionally well in areas that have hitherto been associated with the opposite gender. It would be unwise therefore for society to set up rigid gender roles and deny such individuals the opportunities that will enable them achieve self realization and in the same vein contribute their quota towards national development. In it is regard, the development of female football by various governments and private organizations is to be commended and mere efforts encouraged towards this direction.

3. In view of the above enlightenment, socialization then should not be a rigid process tailored to hammer individuals into expected gender roles. There should be room for observation of individual traits and a willingness to encourage each person (including those who deviate from the regular pattern) to be the best of what they can be.

4. In Nike primal community, both men and women acted effectively as religious leaders (priests). This is a pointer to the fact that there are abilities that do not occur along the lines of sex. These include leadership and organizational abilities and no one should be denied an opportunity to contribute their quota or excel in these areas in the name of God.

\section{Conclusion}

Gender based role differentiation initiated a kind of seasonally defined division of responsibilities in Nike primal community. A man feeds his household at a particular time of the year and the 
woman is leaned upon to put the family through during a period of seasonal poverty or hunger gap. Everyone is fully aware of the part he or she is expected to play, and earns due respect for a job well done. To call a spade a spade, gender disparity and patriarchal tendencies are antithetical to the self esteem of individuals and to the unity and progress of the society as a whole. On the other hand, the allocation of roles to the different sexes purely based on the knowledge of the difference on the biological characteristics of the male and female gender is in resonance with nature and will benefit society tremendously especially in the area of production of goods and services. However, there is need to remove the element of rigidity, suppression and gender disparity.

\section{Uchechukwu Monica Ejim}

University of Nigeria, Nsukka uchem75@gmail.com

\section{References}

Agha, U. A. (2012). Religion and Culture in a Permissive Society. Enugu: Idika Press (Nig).

Amadiume, I. (1987). Male Daughters, Female Husbands: Gender and Sex in an African Society. London: Zed Books Ltd.

De Garine, I. (1991). Seasonal food shortage famine and socio economic change among the massan and Mussey at Northern Cameroon. In H. G. Bolle, T. Canon, C. Hugo \& F. N. Ibrahim (eds) famine and food. Security in Africa and Asia (pp. 83-84). Bayreute: Naturio Wissencha Etuche Gessellschaff.

Dolen, R. D. (2008). Sex difference versus Dogma. Retrieved from, becoming.org/sexRole-3.htm on 29/5/2015. 
Haralambos, M. and Heald, R. M. (1980). Sociology: Themes and Perspectives. New Delhi: Oxford University Press.

Iyam, D. U. (1995). The Broken Hoe. Cultural reconfiguration in Biase, South East Nigeria. Chicago: The University of Chicago Press.

Kalu, O. U. (1996). The embattled gods: Christianization of Igboland, 1841-1911. Lagos: Minaj Publishers.

Kluckhom, C. (1951). The concept of culture in D. Lerner and H.

D. Lass Well (eds) The Policy Sciences. Standford: Stanford University Press.

Linton, R. (1995). Present world conditions in cultural perspective in R. Lonton (ed). The Science of Man in World Crisis. New York: Columbia University Press.

Mabili, S. T. (2013). The role of culture in gender disparity in Africa. Retrieved from, http://www.wikigender.org on 29/5/2015.

Madu, E. M. (1996). Fundamentals of Religious Studies. Calabar, Franedoh Publishers.

Metuh, E. I. (1987). Comparative Studies of Africa Traditional Religion. Onitsha: Imico Publishers.

Nnamani, O. J. (1999). The Legend of a Volitional Confederation. Enugu: Snaap Press (Nig) Ltd.

Parsons, T. (1975). The Social System. Glencoe: Free Press.

Pease, A. and Pease, B. (2001). Why Men Don't Listen and Women Can't Read Maps. London: Orion Books.

Peil, M. (1977). Consensus and Conflict in African Societies London: Longman.

Uchem, R. N. (2001). Overcoming Women's Subordination. Parkland, U.S.A: Dissertation.com. 